\title{
The Influence of the Atmospheric Transmission for the Solar Radiation and Earth's Surface Radiation on the Earth's Climate
}

\author{
Habibullo I. Abdussamatov, Alexander I. Bogoyavlenskii, Sergey I. Khankov, Yevgeniy V. Lapovok \\ Pulkovo Observatory, Saint-Petersburg, Russia \\ E-mail:abduss@gao.spb.ru,albg83@gmail.com \\ Received April 13, 2010; revised May 16, 2010; accepted May 22, 2010
}

\begin{abstract}
The physical and mathematical model of the planetary heat balance is developed to establish the influence of the atmospheric transmission for the solar radiation in the shortwave spectrum range and for the surface IR radiation in the longwave spectrum range on the Earth's climate. It is shown the possibility of the decreasing of the atmospheric and surface temperatures with the decreasing of the atmospheric transmission for IR spectrum range, and this decreasing can't be equilibrated with the change of the atmospheric transmission for the incoming solar radiation.
\end{abstract}

Keywords: Climate, Atmospheric Transmission, Planetary Heat Balance

\section{Introduction}

The climatic anomalies are observed on the different parts of the Earth nowadays. It is important to define the interconnection between these anomalies and the global climate change. The influence of the atmospheric transmission for the heat surface radiation and for the solar incoming radiation on the Earth's heat state is especially interesting. The understanding of this influence makes it possible to specify the influence of the anthropogenic emission of the greenhouse gases (especially of the carbonic dioxide) to the atmosphere on the climate.

To investigate global climatic trends, such parameters as the integral temperature, globally averaged fluxes and averaged albedo are used. Integral parameters are important to create comprehensive numerical models.

The purpose of this work is to provide the integral analytical model of the heat balance for the system of the Earth's surface - the atmosphere - the space and to investigate the influence of main parameters on the Earth's climate. Usually heat balance is describes for latitudes, and vertical profiles for atmospheric parameters and the atmospheric temperature are used [1,2]. In this work the averaged parameters of the system the Earth's surface the atmosphere are used and the averaged temperatures as well. Heat balance is described using the generally accepted termophysical method [3]. Empirical data is used at minimum and missing data is defined from the condition of the heat balance. The influence of atmospheric transparency on the climate is investigated with regard to the integral albedo of the surface and the atmosphere.

Atmospheric transparency for both shortwave and longwave (SW and LW) ranges influences appreciably on the Earth's climate. In this work we characterize the climate state with two temperatures: the surface temperature $T_{\mathrm{s}}$ averaged on the whole surface and the atmospheric temperature $T_{a}$ averaged on both the whole surface and vertical dimension.

\section{Physical Model}

The following limitation is adopted: the dependencies $T_{s}$ $(\gamma, \beta)$ and $\mathrm{T}_{\mathrm{a}}(\gamma, \beta)$ are investigated for the equilibrium heat state. Here $\gamma$ is atmospheric transparency in atomspheric windows for IR range, $\beta$ is atmospheric transparency for shortwave range. As usual, the wavelength 4 $\mu \mathrm{m}$ is considered as the border between the SW and LW ranges. The introduced limitation enables don't make calculations of transient heat processes for every pair of values $\beta$ and $\gamma$.

We use the values of the surface albedo and the surface emissivity averaged on the whole surface of the ocean and the land. These values are obtained from the condi- 
tion of the heat balance. The averaged values of the atmospheric albedo and the atmospheric emissivity are accepted the same in both vertical directions to the space and to the surface. Multiply reflecting of the radiation between the surface and the atmosphere is considered with the values of experimental data [4] used for our calculations. The used value of the atmospheric transmission for the incoming solar radiation is averaged on the whole spectrum. Atmospheric windows are considered for the spectrum of the surface IR radiation (main window is range $8 \ldots 13 \mu \mathrm{m})$.

The limitations and assumptions described above lead to the heat model of the system of the isotermical kernel - the isotermical cover, which are in the equilibrium heat state absorbing the solar radiation and losing heat to the space with radiation. The space temperature is assumed $\mathrm{T}_{\mathrm{s}}=0 \mathrm{~K}$.

\section{Mathematical Model}

To our investigations the equations of the steady-state heat balance of the system of the surface - the atmosphere - the space are used in form

$$
\left.\begin{array}{rl}
-\mathrm{q}_{\mathrm{r}}-\mathrm{q}+\mathrm{q}_{\mathrm{a}} & =\mathrm{Q}_{\mathrm{a}} \\
\mathrm{q}_{\mathrm{r}}+\mathrm{q}+\mathrm{q}_{\mathrm{s}} & =\mathrm{Q}_{\mathrm{s}}
\end{array}\right\} .
$$

here $q_{r}$ - the net specific heat flux from the surface to the atmosphere; $\mathrm{q}$ - the total heat flux from the surface to the atmosphere transferred with convection and evaporation mechanisms; $\mathrm{q}_{\mathrm{a}}$ and $\mathrm{q}_{\mathrm{s}}$ - the specific radiative heat fluxes to the space from the atmosphere and the surface, respectively; $\mathrm{Q}_{\mathrm{a}}$ and $\mathrm{Q}_{\mathrm{s}}$ - the specific fluxes, which are the parts of the incoming solar radiation absorbed by the atmosphere and the surface, respectively.

The fluxes in the left hand sides of the Equations (1) $\mathrm{q}_{\mathrm{r}}$, $\mathrm{q}, \mathrm{q}_{\mathrm{a}}$ and $\mathrm{q}_{\mathrm{s}}$ are forced fluxes created by the forcing fluxes $\mathrm{Q}_{\mathrm{a}}$ and $\mathrm{Q}_{\mathrm{s}}$. These two fluxes make the heat balance. The forced fluxes equal to 0 when $\mathrm{Q}_{\mathrm{a}}=\mathrm{Q}_{\mathrm{s}}=0$.

Forced fluxes are described with formulas

$$
\begin{array}{ll}
\mathrm{q}_{\mathrm{r}}=\mathrm{F} \sigma\left(\mathrm{T}_{\mathrm{s}}^{4}-\mathrm{T}_{\mathrm{a}}^{4}\right) ; & \mathrm{q}=\alpha\left(\mathrm{T}_{\mathrm{s}}-\mathrm{T}_{\mathrm{a}}\right) ; \\
\mathrm{q}_{\mathrm{a}}=\left(1-\gamma \delta_{\mathrm{a}}\right) \varepsilon_{\mathrm{a}} \sigma \mathrm{T}_{\mathrm{a}}^{4} ; & \mathrm{q}_{\mathrm{s}}=\gamma \delta_{\mathrm{s}} \varepsilon_{\mathrm{s}} \sigma \mathrm{T}_{\mathrm{s}}^{4} .
\end{array}
$$

here $\varepsilon_{\mathrm{a}}, \varepsilon_{\mathrm{s}}, \mathrm{F}-$ the emissivities of the atmosphere, the ocean and the transfer factor for the system of the ocean - the atmosphere; $\sigma=5.67 \cdot 10^{-8} \mathrm{~W} \cdot \mathrm{m}^{-2} \mathrm{~K}^{-4}$ - the Ste-fanBoltzmann constant; $\delta_{\mathrm{s}}-$ the fraction of the surface emissive power contained in the atmospheric window, $\delta_{\mathrm{s}}=$ $\delta_{\mathrm{s}}\left(\mathrm{T}_{\mathrm{s}}\right) ; \delta_{\mathrm{a}}$ - the fraction of the atmospheric emissive power contained in the atmospheric window, $\delta_{\mathrm{a}}=\delta_{\mathrm{a}}\left(\mathrm{T}_{\mathrm{a}}\right) ; \alpha$ - the convective and evaporating-condensation conductivity.
We provide the discussion about the influence of the assumption $\alpha=$ const on our results after the calculation result presentation.

The transfer factor [3] is described for our model with ratio

$$
\mathrm{F}=\frac{1}{\frac{1}{\left(1-\gamma \delta_{\mathrm{s}}\right) \varepsilon_{\mathrm{s}}}+\frac{1}{\left(1-\gamma \delta_{\mathrm{a}}\right) \varepsilon_{\mathrm{a}}}-1}
$$

\section{Interconnection among the Heat Balance Components and the Establishing of the Values of the Parameters}

Forcing fluxes are defined as

$$
\left.\begin{array}{l}
Q_{s}=\left(1-A_{a}\right)\left(1-A_{s}\right) \beta Q_{\text {in }} \\
Q_{a}=\left(1-A_{a}\right)(1-\beta) Q_{\text {in }}
\end{array}\right\}
$$

here $\mathrm{A}_{\mathrm{a}}$ - the atmospheric albedo; $\mathrm{A}_{\mathrm{s}}$ - the surface albedo; $\mathrm{Q}_{\text {in }}-$ the incoming solar radiation.

With regard to the value of the solar constant $E=1366$ $\mathrm{W} / \mathrm{m}^{2}$, the value of $\mathrm{Q}_{\text {in }}$ equals to

$$
\mathrm{Q}_{\text {in }}=\mathrm{E} / 4=341.5 \mathrm{~W} / \mathrm{m}^{2} \text {. }
$$

The atmospheric albedo is set with the following rate

$$
\mathrm{A}_{\mathrm{a}}=\mathrm{Q}_{\mathrm{ar}} / \mathrm{Q}_{\text {in }}
$$

here $\mathrm{Q}_{\mathrm{ar}}$ is the part of the solar flux reflected by the atmosphere to the space.

The surface albedo is defined with formula

$$
\mathrm{A}_{\mathrm{s}}=\mathrm{Q}_{\mathrm{sr}} /\left(\mathrm{Q}_{\mathrm{tr}}-\mathrm{Q}_{\mathrm{a}}\right) \text {, }
$$

here $\mathrm{Q}_{\mathrm{sr}}$ is the part of the solar flux reflected by the surface; $\mathrm{Q}_{\mathrm{tr}}$ - the part of the solar flux transferred to the atomsphere, it is defined from rate:

$$
\mathrm{Q}_{\mathrm{tr}}=\left(1-\mathrm{A}_{\mathrm{a}}\right) \mathrm{Q}_{\text {in }} \text {. }
$$

The value of the atmospheric transparency can be defined from (4) with regard to (8)

$$
\beta=1-\mathrm{Q}_{\mathrm{a}} / \mathrm{Q}_{\mathrm{tr}} \text {. }
$$

Planetary albedo of the Earth is defined as

$$
\mathrm{A}_{\mathrm{p}}=\left(\mathrm{Q}_{\mathrm{ar}}+\mathrm{Q}_{\mathrm{sr}}\right) / \mathrm{Q}_{\mathrm{in}} \text {. }
$$

To define all described parameters from (6), (7), (9) and (10), the data [4] about the radiative balance for the incoming solar radiation are used, so the following values of the fluxes $\left(\mathrm{W} / \mathrm{m}^{2}\right)$ are adopted:

$$
\mathrm{Q}_{\mathrm{ar}}=77 ; \mathrm{Q}_{\mathrm{sr}}=30 ; \mathrm{Q}_{\mathrm{a}}=67 ; \mathrm{Q}_{\mathrm{s}}=168 \text {. }
$$

Table 1 contains the values of the atmospheric and surface emissivities, which are calculated with the formulas for $\mathrm{q}_{\mathrm{a}}$ and $\mathrm{q}_{\mathrm{s}}$ from (2) using the values $\mathrm{q}_{\mathrm{s}}=40 \mathrm{~W} / \mathrm{m}^{2}$ and $\mathrm{q}_{\mathrm{a}}=195 \mathrm{~W} / \mathrm{m}^{2}$ [4]. With the known value $\mathrm{T}_{\mathrm{s}}=287 \mathrm{~K}$ the energy fractions for the spectrum range $8 \ldots 13 \mu \mathrm{m}$ are 
Table 1. The results of the parameter calculating using (11).

\begin{tabular}{cccccc}
\hline $\mathrm{A}_{\mathrm{s}}$ & $\mathrm{A}_{\mathrm{a}}$ & $\mathrm{A}_{\mathrm{p}}$ & $\beta$ & $\varepsilon_{\mathrm{s}}$ & $\varepsilon_{\mathrm{a}}$ \\
\hline 0.15 & 0.225 & 0.31 & 0.747 & 0.417 & 0.7 \\
\hline
\end{tabular}

$\delta_{\mathrm{s}}=0.312$ and $\delta_{\mathrm{a}}=0.309$. The last value is obtained from the system (1) with regard to (2) with the set value $\gamma=$ 0.8 and all described parameter values. The values $\mathrm{T}_{\mathrm{a}}=$ $284.25 \mathrm{~K}$ and $\alpha=45.56 \mathrm{~W} / \mathrm{m}^{2} \mathrm{~K}$ are obtained as the additional result. The value of the $\alpha$ is assumed to be constant value for the following calculations.

The total planetary absorbed specific heat flux can be described in the following form based on the obtained dependencies

$$
\begin{aligned}
& \mathrm{Q}_{\Sigma}=\mathrm{Q}_{\mathrm{s}}+\mathrm{Q}_{\mathrm{a}}=\left(1-\mathrm{A}_{\mathrm{p}}\right) \mathrm{Q}_{\mathrm{in}} \\
& \mathrm{A}_{\mathrm{p}}=\mathrm{A}_{\mathrm{a}}+\left(1-\mathrm{A}_{\mathrm{a}}\right) \mathrm{A}_{\mathrm{s}} \beta .
\end{aligned}
$$

Specific fluxes $Q_{s}$ and $Q_{a}$ from (4) can be described with $\mathrm{Q}_{\mathrm{tr}}$ from (8) in form

$$
\begin{aligned}
& \mathrm{Q}_{\mathrm{s}}=\mathrm{Q}_{\mathrm{m}} \beta ; \quad \mathrm{Q}_{\mathrm{a}}=\mathrm{Q}_{\mathrm{tr}}(1-\beta) ; \\
& \mathrm{Q}_{\mathrm{\Sigma}}=\mathrm{Q}_{\mathrm{tr}}\left(1-\mathrm{A}_{\mathrm{s}} \beta\right) ; \\
& \mathrm{Q}_{\mathrm{m}}=\left(1-\mathrm{A}_{\mathrm{s}}\right) \mathrm{Q}_{\mathrm{tr}}=\left(1-\mathrm{A}_{\mathrm{a}}\right)\left(1-\mathrm{A}_{\mathrm{s}}\right) \mathrm{Q}_{\mathrm{tr}} .
\end{aligned}
$$

here $\mathrm{Q}_{\mathrm{m}}$ - the hypothetical maximal specific heat flux which can be absorbed by the Earth in hypothetical case of the totally transparent atmosphere (when $\beta=1$ ).

The values of $Q_{t r}$ and $Q_{m}$ in $W / m^{2}$ with regard to the values of $\mathrm{A}_{\mathrm{s}}$ and $\mathrm{A}_{\mathrm{a}}$ from Table 1 equal

$$
\mathrm{Q}_{\mathrm{tr}}=265 ; \quad \mathrm{Q}_{\mathrm{m}}=225 \text {. }
$$

We obtain from (13) taking into account (14)

$$
\mathrm{Q}_{\mathrm{s}}=225 \beta ; \mathrm{Q}_{\mathrm{a}}=265(1-\beta) ; \mathrm{Q}_{\Sigma}=265-40 \beta
$$

Adopting $\beta \approx 0,75$ (Table 1), it is possible to obtain $\mathrm{Q}_{\Sigma}=235 \mathrm{~W} / \mathrm{m}^{2}$. This value corresponds to the data about integral heat balance [4].

\section{Planetary Integral Model}

The left and right hand sides of the Equation (1) are added with regard to (2), (12) and (13). Assuming $\mathrm{T}_{\mathrm{a}} \approx$ $\mathrm{T}_{\mathrm{s}}$ and $\delta_{\mathrm{s}} \approx \delta_{\mathrm{a}}=\delta$, the formula is obtained which can be used for the estimating of the dependence of the Earth's temperature on $\beta$ and $\gamma$ :

$$
\begin{aligned}
& \mathrm{T}_{\mathrm{p}}=\mathrm{T}_{\mathrm{b}} \mathrm{f} ; \quad \mathrm{T}_{\mathrm{b}}=\mathrm{T}_{\mathrm{p}}(\beta=0 ; \gamma=0)=\sqrt[4]{\mathrm{Q}_{\mathrm{tr}} / \sigma \varepsilon_{\mathrm{a}}} \\
& \mathrm{f}=\sqrt[4]{\varphi} ; \varphi=\frac{1-\mathrm{A}_{\mathrm{s}} \beta}{1-\mathrm{b} \gamma} ; \mathrm{b}=\frac{\varepsilon_{\mathrm{a}}-\varepsilon_{\mathrm{s}}}{\varepsilon_{\mathrm{a}}} \delta .
\end{aligned}
$$

Substituting all the parameter values to (16), we obtain $\mathrm{T}_{\mathrm{p}}=285 \mathrm{~K}$.

It is follows from the structure of the function $f$ that the increasing of the atmospheric transparency for the IR range $\gamma$ causes the increasing of the Earth's temperature if the condition $\varepsilon_{\mathrm{a}}>\varepsilon_{\mathrm{s}}$ is satisfied. The Earth's temperature decreases with the increasing of the atmospheric transparency for SW range $\beta$. The condition of the constancy of the Earth's temperature can be set in form $\mathrm{f}=$ const or $\varphi=$ const. The dependency $\beta(\gamma)$ is found from this condition

$$
\begin{aligned}
& \beta=\left(\varphi_{\mathrm{o}} / \mathrm{A}_{\mathrm{s}}\right) \mathrm{b} \gamma+\left(1-\varphi_{\mathrm{o}}\right) / \mathrm{A}_{\mathrm{s}} ; \\
& \varphi_{\mathrm{o}}=\varphi(\beta=0.747 ; \gamma=0.8)
\end{aligned}
$$

The rate (17) means that the increasing of the outcome heat radiation from the surface must be equilibrate with the increasing of the absorbed heat.

Substituting the parameters from the Table 1 to the formula for $\mathrm{b}(16)$ and establishing the averaged value $\delta$ $=\left(\delta_{\mathrm{s}}+\delta_{\mathrm{a}}\right) / 2 \approx 0.31$, we obtain $\mathrm{b}=0.1253$. With regard to this result $\varphi_{0}=0.9869$. So, it follows from (17)

$$
\beta=0.824 \gamma+0.087 \text {. }
$$

With regard to (12), the Formula (16) is presented in form

$$
\mathrm{T}_{\mathrm{p}}=\sqrt[4]{\frac{\mathrm{E}}{4 \sigma \varepsilon_{\mathrm{a}}} \frac{\mathrm{G}}{\mathrm{D}}} ; \quad \mathrm{D}=1-\mathrm{b} \gamma .
$$

here $\mathrm{G}$ can be described as:

$$
\mathrm{G}=\left(1-\mathrm{A}_{\mathrm{p}}\right)=\left(1-\mathrm{A}_{\mathrm{a}}\right)\left(1-\mathrm{A}_{\mathrm{s}} \beta\right)
$$

The Formula (20) makes it possible to specify the general discussion about the albedo influence on the climate and to provide distinguish between the surface albedo $A_{s}$ and the atmospheric albedo $A_{a}$. The effective albedo change as a result of the surface or atmospheric albedo change can be obtained from (12)

$$
\begin{aligned}
\Delta \mathrm{A}_{\mathrm{p}}\left(\Delta \mathrm{A}_{\mathrm{s}}\right)=\frac{\mathrm{dA}_{\mathrm{p}}}{\mathrm{dA}_{\mathrm{s}}} \Delta \mathrm{A}_{\mathrm{s}}= \\
=\left(1-\mathrm{A}_{\mathrm{a}}\right) \beta \Delta \mathrm{A}_{\mathrm{s}}=0.579 \Delta \mathrm{A}_{\mathrm{s}} ; \\
\begin{aligned}
\Delta \mathrm{A}_{\mathrm{p}}\left(\Delta \mathrm{A}_{\mathrm{a}}\right)= & \frac{\mathrm{dA}_{\mathrm{p}}}{\mathrm{dA}_{\mathrm{a}}} \Delta \mathrm{A}_{\mathrm{a}}= \\
= & \left(1-\mathrm{A}_{\mathrm{s}} \beta\right) \Delta \mathrm{A}_{\mathrm{a}}=0.888 \Delta \mathrm{A}_{\mathrm{a}} .
\end{aligned}
\end{aligned}
$$

The change of the surface albedo is considered as an important indicator of the Earth's temperature state, because the increasing of the glacial cover based on the temperature decreasing causes the increasing of the albedo, and this causes the next temperature decreasing. As it seen from (21), the change of the atmospheric albedo influences on the effective albedo 1.5 times more than the change of the surface albedo. The increasing of the value of the effective albedo can be caused by the cloudiness increasing which can be caused by the warming. So, it should be noted that the results of the measurement of the effective albedo is not enough to make a 
diagnosis of the climate variations, with regard to the fact that the warming causes the increasing of $\mathrm{A}_{\mathrm{a}}$ and the decreasing of $\mathrm{A}_{\mathrm{s}}$.

It is important to notice, that quantities $A_{s}$ and $A_{a}$ are independent characteristics, but the effective Earth's albedo depends on the atmospheric transmission for SW range, as it seen from (12).

With regard to the data from Table 1, the dependencies $A_{p}(\beta)$ and $\Delta A_{p}(\Delta \beta)$ are described with formulas

$$
\begin{aligned}
& \mathrm{A}_{\mathrm{p}}=0.225+0.116 \beta \\
& \Delta \mathrm{A}_{\mathrm{p}}(\Delta \beta)=\frac{\mathrm{dA}}{\mathrm{d} \beta} \Delta \beta=0.116 \Delta \beta .
\end{aligned}
$$

So, if $A_{s}$ and $A_{a}$ are constant values, then $A_{p}$ can hypothetically change in 1.5 times, from $A_{p}=0.225$ with $\beta$ $=0$ to $A_{p}=0.341$ with $\beta=1$. The influence of $\beta$ variations on the changing of $A_{p} 5$ times less than influence of $A_{s}$ variations on the changing of $A_{p}$.

With regard to the data from Table 1, the quantity dependence $A_{a}(\gamma)$ is obtained from (19) and (20). The Earth's averaged temperature is constant when this dependence is satisfied

$$
\mathrm{A}_{\mathrm{a}}=0.108 \gamma+0.139
$$

Next results are followed from the comparing of the dependencies (18) and (23). When $\gamma$ changes from 0 to 1 , then $\beta$ must change from 0.087 to 0.911 that is an order of magnitude, and the value $A_{a}$ must change from 0.139 to 0.247 that is less then 2 times. It means that the decrease of the atmospheric transmission for the surface heat radiation can be equilibrated by the decrease of the transmission for the solar radiation with the same order of magnitude $(\Delta \beta \approx 0.8 \Delta \gamma)$. To equilibrate the decrease of $\gamma$, it is necessary the decrease of the atmospheric albedo in form $\Delta \mathrm{A}_{\mathrm{a}} \approx 0.1 \Delta \gamma$.

\section{Results of the Calculations Based on the System of the Equations}

Planetary model of the Earth is useful to find the more general dependencies of the planetary heat behavior, but it has some limitations. The variations of the heat balance components in the system of the atmosphere - the surface influence on the climate change, but it can't be investigated with this planetary model.

Results of the more detailed investigations are shown in Figures 1-4. These investigations are based on the solving of the system of the Equation (1) with regard to (2).

Figure 1 shows the dependencies of the surface temperature and the atmospheric temperature on the atmospheric transmission for the atmospheric window $8 \ldots 13$ $\mu \mathrm{m}, \beta=0.747$ and for the boundary values $\beta=0$ and $\beta=$
1. The calculations are done for the full hypothetically possible range $0 \leq \gamma \leq 1$, so the behavior of the dependencies is clear and also the limit cases can be analyzed. The curves in Figure 1 close to linear ones, their saliencies are directed down. So, the parts of the curves can be precisely approximated by the linear rates for the limited ranges of $\gamma$ changes (for example for the range $0.8 \pm 0.1$ ). It can be seen the increasing of the temperatures with the increasing of $\gamma$. This result is in agreement with the result described early for the rate (16). It means that the increasing of the greenhouse gases concentration should cause the global cooling. This result doesn't depend on the value of the atmospheric transmission for SW, it can be $0 \leq \beta \leq 1$.

To expose the causes of described results, it is necessary to examine the dependencies of the heat balance components on $\gamma$. Table 2 contains the values of the components for the limiting values of $\gamma$ with $\beta=0.747$.

The heat balance $\mathrm{q}_{\mathrm{s}}+\mathrm{q}_{\mathrm{a}}=\mathrm{Q}_{\Sigma}=235 \mathrm{~W} / \mathrm{m}^{2}$ is saved for any value of $\gamma$. So, the power radiated totally by the planet equals to the absorbed power from the Sun. It doesn't depend on the dividing of the flux powers between the surface and the atmosphere. But the averaged temperatures are not constant. The total power of the fluxes from the surface to the atmosphere $\mathrm{q}_{\mathrm{r}}+\mathrm{q}=118 \mathrm{~W} / \mathrm{m}^{2}$ with

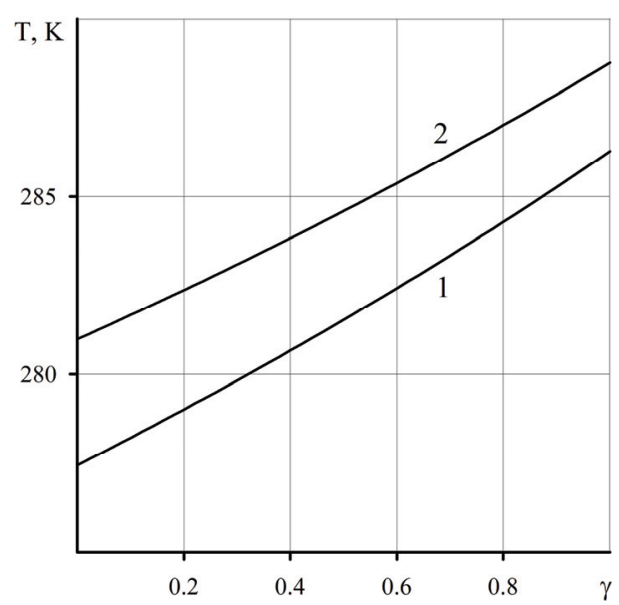

Figure 1. The dependencies of the atmospheric temperature (1) and the surface temperature (2) on the atmospheric transmission for IR range $\gamma$ when the atmospheric transmission for the solar radiation $\beta=0.747$.

Table 2. The maximal and minimal values of the specific heat fluxes from the equation system (1).

\begin{tabular}{ccccc}
\hline & \multicolumn{4}{l}{ The values of the specific heat fluxes $\mathrm{W} / \mathrm{m}^{2}$} \\
\cline { 2 - 5 } & $\mathrm{q}_{\mathrm{r}}$ & $\mathrm{q}$ & $\mathrm{q}_{\mathrm{s}}$ & $\mathrm{q}_{\mathrm{a}}$ \\
\hline 0 & 8 & 160 & 0 & 235 \\
1 & 3 & 115 & 50 & 185 \\
\hline
\end{tabular}


$\gamma=1$ and $\mathrm{q}_{\mathrm{r}}+\mathrm{q}=168 \mathrm{~W} / \mathrm{m}^{2}$ with $\gamma=0$. The difference is $50 \mathrm{~W} / \mathrm{m}^{2}$, it is the value of $\mathrm{q}_{\mathrm{s}}(\gamma=1)$. So, the decreasing of $\gamma$ causes the increasing of the power absorbed by the atmosphere, and this power re-radiated by the atmosphere to the space. It causes the decreasing of the atmospheric temperature. As the atmosphere is the cover for the surface, the surface is cooling too.

It is important to note that the described results are correct when the condition $\varepsilon_{\mathrm{a}}>\varepsilon_{\mathrm{s}}$ is performed. As calculations shown, the dependencies $\mathrm{T}_{\mathrm{s}}(\gamma)$ and $\mathrm{T}_{\mathrm{a}}(\gamma)$ decrease in the case $\varepsilon_{\mathrm{a}}<\varepsilon_{\mathrm{s}}$. The condition $\varepsilon_{\mathrm{a}}=\varepsilon_{\mathrm{s}}$ is the border between these cases. This condition corresponds to the value $\mathrm{q}_{\mathrm{s}} \approx 60 \mathrm{~W} / \mathrm{m}^{2}, \varepsilon_{\mathrm{a}}=\varepsilon_{\mathrm{s}}=0.7$ and the values of all other parameters keep constant. Actually, the decreasing of the atmospheric transmission causes the global cooling in the case of initial state $\gamma=0.8$ only when the condition $\mathrm{q}_{\mathrm{s}} \leq 0.25 \mathrm{q}_{\mathrm{a}}$ is satisfied.

Note, that the radiative heat transfer doesn't take main part in the heat transfer between the surface and the atmosphere. This heat transfer is mainly defined by the convection and the condensation-evaporation.

Note, that the value of atmospheric transmission in SW $\beta$ influences weakly on the dependencies $\mathrm{q}_{\mathrm{s}}(\gamma)$ and $\mathrm{q}_{\mathrm{a}}(\gamma)$. Both these dependencies are quite linear, first one is a directly proportional one $\mathrm{q}_{\mathrm{s}}=\mathrm{q}_{\mathrm{m}} \gamma$. The coefficient equals $\mathrm{q}_{\mathrm{m}}=50 \mathrm{~W} / \mathrm{m}^{2}$ when $\beta=0.747$. The value of $\mathrm{q}_{\mathrm{m}}$ changes weakly - from $\sim 49 \mathrm{~W} / \mathrm{m}^{2}$ when $\beta=1$ to $\sim 56$ $\mathrm{BT} / \mathrm{M}^{2}$ when $\beta=0$.

The values $\mathrm{q}_{\mathrm{a}}$ for $\beta=0.747$ and the boundary values of $\beta$ and $\gamma$ are shown in Table 3.

Figure 2 shows the dependencies $\beta(\gamma)$ calculated from the system (1) in comparison with the dependence (18). The only one condition can be satisfied: $\mathrm{T}_{\mathrm{s}}=$ const or $\mathrm{T}_{\mathrm{a}}$ = const. If any temperature is constant then another temperature will change. This fact is shown in Figure 4 in terms of quantity. It makes it impossible to keep the heat balance for the system of the surface - the atmosphere, so actually the compensating of the $\gamma$ change with the $\beta$ change isn't possible.

Figure 3 shows the dependence of the atmospheric albedo on $\gamma$ which ensure the constancy of the surface temperature $\mathrm{T}_{\mathrm{s}}$ (the curve 1) or the atmospheric temperature $T_{a}$ (the curve 2) and also of the averaged temperature of the system of the surface - the atmosphere (dash-

Table 3. The values of the fluxes $q \mathrm{a} \mathrm{W} / \mathrm{m}^{2}$ radiated by the atmosphere to the space.

\begin{tabular}{cccc}
\hline \multirow{2}{*}{$\begin{array}{c}\text { Table } \\
\text { Head }\end{array}$} & \multicolumn{3}{c}{ The values of $\mathrm{q}_{\mathrm{a}}$} \\
\cline { 2 - 4 } & $\beta=0$ & $\beta=1$ & $\beta=0.747$ \\
\hline 0 & 260 & 225 & 235 \\
1 & 205 & 175 & 185 \\
\hline
\end{tabular}

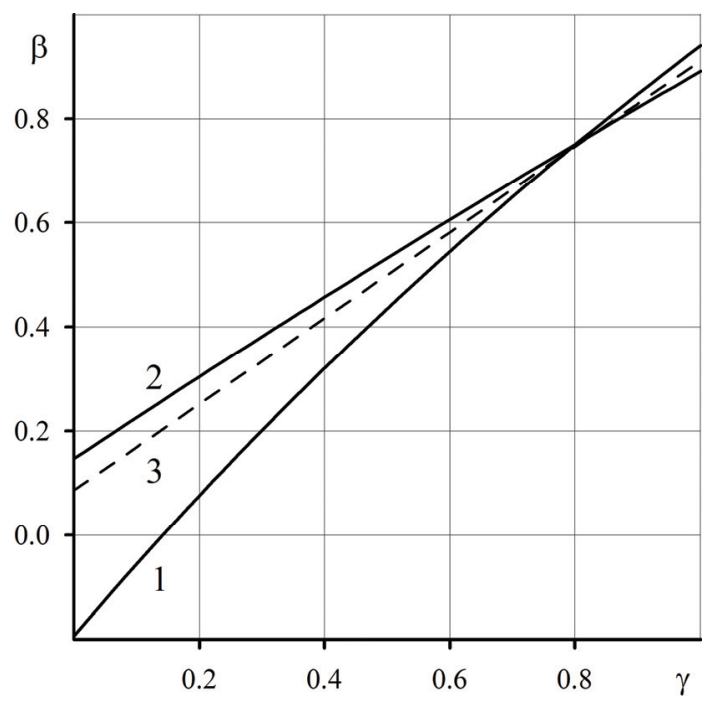

Figure 2. The dependence of the atmospheric transmission for the solar radiation on the atmospheric transmission for the surface heat radiation making the constant value $T s=$ $287 \mathrm{~K}$ (1) or Ta $=284.25 \mathrm{~K}$ (2). The dot line shows the dependence (18).

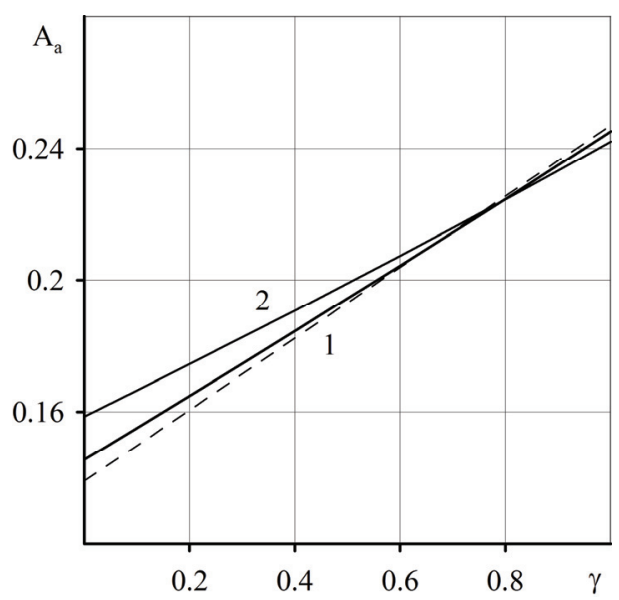

Figure 3. The dependencies $\operatorname{Aa}(\gamma)$ for the cases of constant temperatures Ts (1), Ta( $\gamma)(2), \operatorname{Tp}$ (dashed line).

ed-line curve). The mismatch of the curves 1 and 2 shows that it is impossible to compensate the $\gamma$ change with the atmospheric albedo change. It causes from the data presented in Figure 4

Results presented in Figures 2-4 have shown that projects of the scattering of the absorbing aerosol or reflecting aerosol are not scientifically grounded definitely; it is possible to provide the approach resulting to the deduction that this scattering is rather dangerous.

The assumption $\alpha=$ const is adopted for our calculations. It is discussed below. Generally, the convective and evaporating coefficient $\alpha$ depends on the temperature 


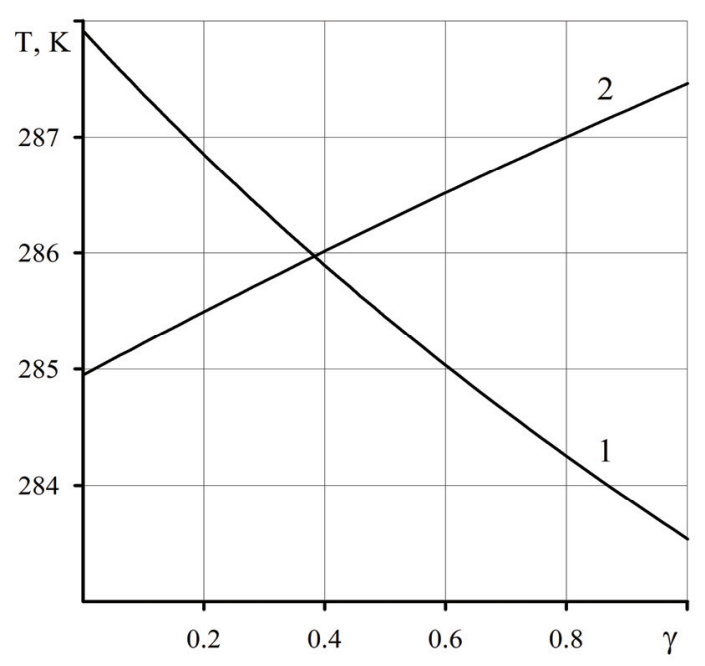

Figure 4. The dependencies $\operatorname{Ta}(\gamma)(1)$ and $\operatorname{Ts}(\gamma)(2)$ corresponding to the curve 1 and the curve 2 on Figure 2, respectively.

difference $\Delta \mathrm{T}_{\mathrm{sa}}=\mathrm{T}_{\mathrm{s}}-\mathrm{T}_{\mathrm{a}}$ and on the temperature level. For the dependence $\alpha\left(T_{a}\right)$ it is important that that dependencies of air thermophysical properties on its temperature are weak. Calculations show the atmospheric temperature change from $\mathrm{T}_{\mathrm{a}} \approx 277 \mathrm{~K}$ to $\mathrm{T}_{\mathrm{a}} \approx 286 \mathrm{~K}$ (about $\sim 9$ $\mathrm{K})$ with $\gamma$ change from 0 to 1 . The specific air heat capacity is constant $\left(c_{\mathrm{p}}=1,005 \mathrm{~kJ} / \mathrm{kg} \mathrm{K}\right)$, the Prandtl number (Pr) change is less then $0,5 \%$. Air density $\left(\rho, \mathrm{kg} / \mathrm{m}^{3}\right)$ is decreased on $\sim 5 \%$, the heat conduction $(\lambda, \mathrm{W} / \mathrm{mK})$ is decreased on $\sim 5 \%$, and the kinematic viscosity $\left(v, \mathrm{~m}^{2} / \mathrm{s}\right)$ is increased on $\sim 5 \%$. Calculations based on the assumption $\alpha=$ const show the temperature drop $\Delta \mathrm{T}_{\mathrm{sa}}$ is decreased on $\sim 30 \%$ (from $3,5 \mathrm{~K}$ to $2,5 \mathrm{~K}$ ) with the increasing of $\gamma$ from 0 to 1 .

The analysis of the equations describing the convective heat transfer with Nusselt, Grashof and Prandtl numbers [5] shows the decreasing of $\alpha$ on $\sim 15 \%$ with the increasing of $\gamma$ from 0 to 1 with regard to mass transfer.

The behavior of the dependencies $\mathrm{T}_{\mathrm{s}}(\gamma)$ and $\mathrm{T}_{\mathrm{a}}(\gamma)$ with the change of $\alpha$ from $\alpha=40 \mathrm{~W} / \mathrm{m}^{2} \mathrm{~K}$ to $\alpha=50 \mathrm{~W} / \mathrm{m}^{2} \mathrm{~K}$ (about $\sim 20 \%$ around the basic value $45,55 \mathrm{~W} / \mathrm{m}^{2} \mathrm{~K}$ ) were investigated. The important regularity was found. The change of the temperatures rise isn't more than $\sim 0,02 \mathrm{~K}$ for the range $40 \leq \alpha \leq 50$, so the variations of $\alpha$ causes the calculating error about $0,2 \%$. It can be concluded that the heat transfer between the surface and the atmosphere influences on the dependencies $\mathrm{T}_{\mathrm{s}}(\gamma)$ and $\mathrm{T}_{\mathrm{a}}(\gamma)$ weakly. These dependencies are mostly determinated by the radiative balance and by the change of the radiative heat fluxes from the surface and the atmosphere to the space. The value of $\alpha$ establishes the basic value of the temperature $T_{a}$ with the set value of $T_{s}$. It indicates on the possibility to use the assumption $\alpha=$ const for the investigations of the surface and atmospheric temperature dependencies on the atmospheric transmission.

\section{Conclusions}

- The decreasing of the atmospheric transmission for the surface radiation should cause the global cooling with the set of the parameters of the system of the surface - the atmosphere. So, the conception of the increasing of the greenhouse gases concentration and, as a result, the warming is required to be revisited. Small variations of the heat balance [6] for the system of the surface - the atmosphere don't influence on the described results. Obtained results are in good agreement with the results from the work [7];

- the Earth's effective albedo are defined by the values of the atmospheric and surface albedo and by the atmospheric transmission for the solar radiation as well; the effective albedo seems as a mixed criteria of the climate state;

- the indemnity of the change of the atmospheric transmission for the surface radiation with the change of the transmission for the incoming solar radiation or the atmospheric albedo doesn't look as a possible action. The attempts to use the reflecting aerosols or absorbing aerosols are the dangerous operations.

Some additional remarks:

- The behavior of the temperature dependencies on $\gamma$ is independent from taking into account all atmospheric windows or ignoring some of them. And more, assuming $\delta=1$, we didn't find the quality changes of the dependencies $\mathrm{T}_{\mathrm{s}}(\gamma)$ and $\mathrm{T}_{\mathrm{a}}(\gamma)$. Calculations have shown the increasing of the temperatures with the increasing of $\gamma$ for the spectrum range $13 \ldots 17.5 \mu \mathrm{m}$, where the surface radiation is almost totally absorbed by carbon dioxide and water vapor.

- Calculations for the hypothetically possible range 0 $\leq \gamma \leq 1$ make it possible to find the behavior of the dependencies $T_{s}(\gamma)$ and $T_{a}(\gamma)$. These dependencies are monotony. Note that the limitation of the range of the possible transmission variations can reach to the incorrect results. In particular, the assumption $\mathrm{q}=$ const can be accepted to solve the system (1), but it can be seen for the full range of $\gamma$ change that the dependencies $\mathrm{T}_{\mathrm{s}}(\gamma)$ and $\mathrm{T}_{\mathrm{a}}(\gamma)$ intersect each other, i.e., the convective-evaporative flux $\mathrm{q}$ is changed and it's sigh is changed. Last result contradicts to the assumption $\mathrm{q}=$ const. But for the case $\mathrm{q}=$ const the calculations shows the increasing of the surface temperature caused by the decreasing of the transmission for the surface IR radiation. 


\section{References}

[1] S. Manabe and R. F. Strickler, "Thermal Equilibrium of the Atmosphere with a Convective Adjustment," Journal of Atmospheric Science, Vol. 21, Vol. 6, 1964, pp. 361385.

[2] V. Ramanathan, "The Role of Ocean-Atmosphere Interactions in the $\mathrm{CO}_{2}$ Climate Problem," Journal of Atmospheric Science, Vol. 38, Vol. 5, 1981, pp. 918-930.

[3] H. John, I. V. Lienhard and V. Lienhard, "A Heat Transfer Textbook," 3rd Edition, Phlogiston Press, Cambridge, 2008.

[4] J. T. Keihl and K. E. Trenberth, "Earth's Annual
Global Mean Energy Budget," Bulletin of the American Meteorological Society, Vol. 78, No. 2, 1997, pp. 97-208.

[5] E. R. G. Ekkert and R. M. Drake, Jr., "Analysis of Heat and Mass Transfer," Hemisphere Publishing Corp., Washington, D.C., 1987.

[6] K. E. Trenberth, J. T. Fasullo and J. T. Keihl, "Earth's Global Energy Budget," Bulletin of the American Meteorological Society, Vol. 90, No. 3, 2009, pp. 311-323.

[7] G. V. Chilingar, L. F. Khilyuk and O. G. Sorokhtin, "Cooling of Atmosphere Due to $\mathrm{CO}_{2}$ Emission," Energy Sources, Part A: Recovery, Utilization, and Environmental Effects, Vol. 30, No. 1, 2008, pp. 1-9. 